Geriatric Problem

$\%$ present

Lack of Social Support

Incomplete Vaccination

Problems with Cognition

Problems with Chronic Pain

Problems with Dizziness

Problems with Mobility

Problems with Unintentional Weight Loss

Inappropriate Medications present

Polypharmacy present

Frailty present

Short Physical Performance Battery low

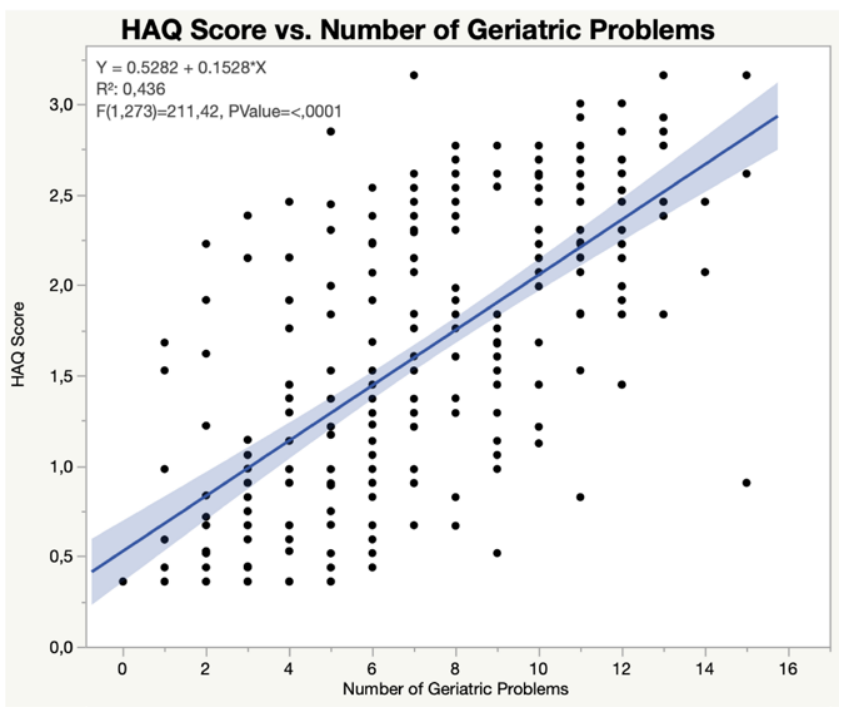

Acknowledgments: None

Disclosure of Interests: Anna Berrisch: None declared, loana Andreica: None declared, Styliani Tsiami: None declared, David Kiefer Grant/research support from: Novartis, Uta Kiltz Grant/research support from: AbbVie, Amgen, Biogen, Novartis, Pfizer, Consultant of: AbbVie, Biocad, Eli Lilly and Company, Grünenthal, Janssen, Novartis, Pfizer, UCB, Speakers bureau: AbbVie, MSD, Novartis, Pfizer, Roche, UCB, Xenofon Baraliakos Grant/research support from: Grant/ research support from: AbbVie, BMS, Celgene, Chugai, Merck, Novartis, Pfizer, UCB and Werfen, Consultant of: AbbVie, BMS, Celgene, Chugai, Merck, Novartis, Pfizer, UCB and Werfen, Speakers bureau: AbbVie, BMS, Celgene, Chugai, Merck, Novartis, Pfizer, UCB and Werfen, Juergen Braun Grant/research support from: Abbvie (Abbott), Amgen, BMS, Boehringer, Celgene, Celltrion, Centocor, Chugai, Eli Lilly and Company, Medac, MSD (Schering Plough), Mundipharma, Novartis, Pfizer (Wyeth), Roche, Sanofi- Aventis, and UCB Pharma, Consultant of: Abbvie (Abbott), Amgen, BMS, Boehringer, Celgene, Celltrion, Centocor, Chugai, EBEWE Pharma, Eli Lilly and Company, Medac, MSD (Schering-Plough), Mundipharma, Novartis, Pfizer (Wyeth), Roche, Sanofi-Aventis, and UCB Pharma, Speakers bureau: Abbvie (Abbott), Amgen, BMS, Boehringer, Celgene, Celltrion, Centocor, Chugai, EBEWE Pharma, Eli Lilly and Company, Medac, MSD (Schering-Plough), Mundipharma, Novartis, Pfizer (Wyeth), Roche, Sanofi-Aventis, and UCB Pharma, Bjoern Buehring Grant/research support from: GE/Lunar, Kinemed, Consultant of: Gilead, Abbvie, Lilly, GE/Lunar, Janssen, Amgen, Speakers bureau: UCB

DOI: 10.1136/annrheumdis-2020-eular.2815

\section{SAT0580 ANALYSIS OF ANAS/DFS70 PATTERN IN A LARGE COHORT OF AUTOIMMUNE/AUTOINFLAMMATORY DISEASES COMPARED WITH FIRST DEGREE RELATIVES AND HEALTHY CONTROLS EVALUATED IN A SINGLE HOSPITAL FROM COLOMBIA.}

C. Romero-Sánchez ${ }^{1,2,3}$, O. J. Calixto ${ }^{4}$, V. Romero- ${ }^{1,2}$, A. Vargas ${ }^{5}$, L. Castro ${ }^{6}$, J. Amador ${ }^{6}$, P. Lopez-Mojica ${ }^{6}$, D. Marin ${ }^{6}$, D. Acero-M ${ }^{2,7}$, M. Acevedo ${ }^{2,7}$, D. Rincón-Riaño ${ }^{1}$, J. M. Bello-Gualtero ${ }^{1,2} \cdot{ }^{1}$ Rheumatology and Immunology Department Hospital Militar Central, Bogota, Colombia; ${ }^{2}$ Clinical Immunology Group- Hospital Militar, School of Medicine, Universidad Militar Nueva Granada, Bogota, Colombia; ${ }^{3}$ Universidad El Bosque, Cellular and Immunology Group IInmuBo, Bogota, Colombia; ${ }^{4}$ Internal Medicine Department Hospital Militar Central, Universidad Militar Nueva Granada, Bogota, Colombia; ${ }^{5}$ Bacteriology degree, Faculty of Basic Sciences, Universidad Colegio Mayor de Cundinamarca, Bogota, Colombia; ${ }^{6}$ Dermatology Department Hospital
Militar Central, Universidad Militar Nueva Granada, Bogota, Colombia; ${ }^{7}$ Immunology Laboratory, Hospital Militar Central, Bogota, Colombia

Background: Autoimmune diseases have a broad phenotypic spectrum, with great variability in clinical manifestations. Anti-DFS70/LEDGFp75 (ANAS/ DFS70) antibodies have attracted interest as a positive result in patients without clinical evidence of autoimmune systemic rheumatic disease (SARD). It has been proven in non-rheumatic inflammatory diseases and in "apparently healthy" individuals.

Objectives: To assess ANAS/DFS70 performance in a large population with autoimmune/autoinflammatory diseases compared with first degree relatives and healthy controls.

Methods: A cross-sectional study was conducted. We analysed 531 individuals between 18-65 years old, 101 rheumatoid arthritis (RA) patients (ACR/EULAR 2010 classification criteria), 137 relatives from RA, 60 psoriasis (Ps) patients (Colombian classification consensus), 47 Undifferentiated connective tissue diseases(UCTD) patients and 186 healthy controls matched by age and sex. The healthy control group were individuals who lived and work similarly like those patients those criteria of exclusion criteria were to present autoimmune or auto-inflammatory disease, infectious, neoplasms, diabetes, antibiotic treatment, pregnancy or lactation, consanguinity with autoimmune entities. Ethical Committee approved.

The determination of ANAS-HEp2 antibodies (ANA-Hep-2 AESKU.Dignostic $®$, Autoantiboy test SYSTEM IMCO DIAGNOSTICS REF $1103 \otimes$ and ANA-Hep-2 AESKU.Dignostic $囚$ ) was carried out. The positive results (standard AC-2) are used as a confirmatory test the determination of ANAS / DFS70: AUTOANTIBOY TEST SYSTEM IMMCO DIAGNOSTICS (Knocked out, for the psip gene) REF $1108 \AA$ and CytoBead ANA Generic Assays ref $8065 \AA$ by indirect immunofluorescence-IFI technique. In addition, serum levels of C-reactive protein (PCR), erythrocyte sedimentation rate (ESR), IgG/lgA antibodies against citrullinated peptide (ACPA), and rheumatoid factor (RF). Absolute and relative frequencies were established.

Results: 531 participants were included: RA 19\%, 25,8\% RA relatives, Ps 11,3\%, UCTD $8,9 \%$, and $35 \%$ healthy controls. RA mean age was $41,8 \pm 12,2$ years,

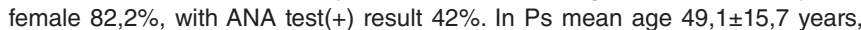
female $53,3 \%$, ANA test(+) $41,7 \%$. UCTD mean age $41,3 \pm 15,2$ years, female $85,1 \%$, and ANA test(+) $78,7 \%$. Relatives of RA mean age $38,7 \pm 12,2$ years female $73 \%$, ANA test(+) $26,3 \%$. And healthy controls mean age $41,3 \pm 12,2$ years, female $74,7 \%$, and ANA test(+) $26,9 \%$.

ANA/DFS70 was positive in a $6,4 \%$ in UCTD, $3,2 \%$ in healthy controls, $1,7 \%$ in Ps, $1,5 \%$ in Relatives of RA, no RA had positive results. These 12 participants were negative for acute phase reactants (ESR[-] 83,3\% and CRP[-] 66,6\%), as well as they were all negative for RF and two were positive for APCA from UCTD.

Conclusion: ANAS/DFS70 autoantibodies were present in very low frequency in patients with SARD. Thus, patients with a positive result tend to have a mild or non-progressing phenotype of autoimmune/inflammatory diseases, as UTCD. This is the first time ANA/DFS70 are tested in a large population cohort in Latin American countries which coincide with previous results in RA and RA relatives.

Acknowledgments: Hospital Militar Central-Universidad El Bosque-Immco diagnosis-Dizar Ltda and Generic Assay-Medipan.

Disclosure of Interests: Consuelo Romero-Sánchez: None declared, OmarJavier Calixto Employee of: Worked in Janssen Cilag as medical manager from 2016 to 2018, V Romero-A: None declared, A Vargas: None declared, Luis Castro: None declared, Julio Amador: None declared, Pedro Lopez-Mojica: None declared, Daniela Marin: None declared, Diana Acero-M: None declared, M Acevedo: None declared, Diana Rincón-Riaño: None declared, Juan Manuel Bello-Gualtero: None declared

DOI: 10.1136/annrheumdis-2020-eular.5082

\section{SAT0581 SERIOUS INFECTION RATES WITH BIOLOGICAL DISEASE MODIFYING ANTI-RHEUMATIC AGENTS (BDMARDS) AND PREDISPOSING FACTORS: A 5-YEAR RETROSPECTIVE REVIEW}

K. Celkys ${ }^{1}$, J. Ly ${ }^{1}$, M. Soden ${ }^{1} .{ }^{1}$ Townsville Hospital and Health Service, Townsville, Australia

Background: Biological and targeted synthetic disease modifying anti-rheumatic agents (bDMARDs) increase the risk of serious infections (SIs), however there is limited 'real-world' evidence comparing the relative risk of SI for individual bDMARDs. $(1,2)$

Objectives: This study examines the rates of Sls in a non-select Australian Northern Queensland (NQ) cohort of patients with various rheumatic diseases receiving treatment with a $b D M A R D$, to define predisposing factors and directly compare the bDMARDs.

Methods: A retrospective review was performed for all patients who received a bDMARD through the Townsville Hospital Rheumatology Department over the 